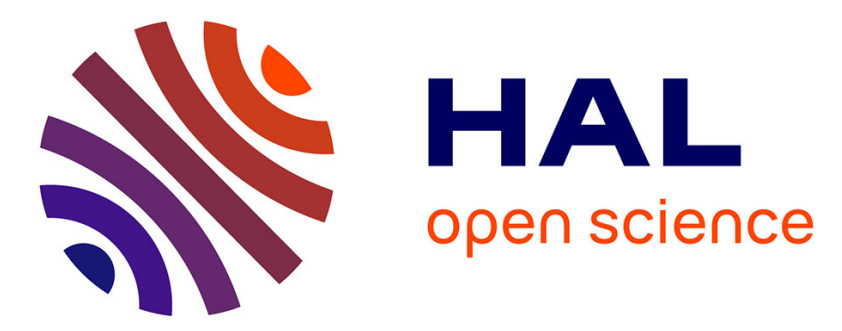

\title{
Glucose-dependent insulinotropic polypeptide receptor deficiency leads to modifications of trabecular bone volume and quality in mice.
}

Christine Gaudin-Audrain, Nigel Irwin, Sity Mansur, Peter-R. Flatt, Bernard Thorens, Michel-Félix Baslé, Daniel Chappard, Guillaume Mabilleau

\section{To cite this version:}

Christine Gaudin-Audrain, Nigel Irwin, Sity Mansur, Peter-R. Flatt, Bernard Thorens, et al.. Glucosedependent insulinotropic polypeptide receptor deficiency leads to modifications of trabecular bone volume and quality in mice.. BONE, 2013, 53, pp.221-30. 10.1016/j.bone.2012.11.039 . hal-03262117

\section{HAL Id: hal-03262117 \\ https://univ-angers.hal.science/hal-03262117}

Submitted on 16 Jun 2021

HAL is a multi-disciplinary open access archive for the deposit and dissemination of scientific research documents, whether they are published or not. The documents may come from teaching and research institutions in France or abroad, or from public or private research centers.
L'archive ouverte pluridisciplinaire HAL, est destinée au dépôt et à la diffusion de documents scientifiques de niveau recherche, publiés ou non, émanant des établissements d'enseignement et de recherche français ou étrangers, des laboratoires publics ou privés. 


\title{
Glucose-dependent insulinotropic polypeptide receptor deficiency leads to modifications of trabecular bone volume and quality in mice
}

\author{
Christine Gaudin-Audrain a , Nigel Irwin b , Sity Mansur b , Peter R. Flatt b , Bernard Thorens c, \\ Michel Baslé ${ }^{\mathrm{a}}$, Daniel Chappard ${ }^{\mathrm{a}}$, Guillaume Mabilleau ${ }^{\mathrm{a}, *}$ \\ a LUNAM Université, GEROM-LHEA, Institut de Biologie en Santé, Angers, France \\ b School of Biomedical Sciences, University of Ulster, Coleraine, UK \\ c Center for Integrative Genomics, University of Lausanne, Lausanne, Switzerland
}

\section{A R T I C L E I N F O}

\section{Article history:}

Received 13 July 2012

Revised 13 November 2012

Accepted 28 November 2012

Available online 6 December 2012

Edited by: David Burr

\section{Keywords:}

Glucose-dependent insulinotropic

polypeptide

Bone microarchitecture

Bone quality

Adipokine

Incretin

\begin{abstract}
A B S T R A C T
A role for the gastro-intestinal tract in controlling bone remodeling is suspected since serum levels of bone remodeling markers are affected rapidly after a meal. Glucose-dependent insulinotropic polypeptide (GIP) represents a suitable candidate in mediating this effect. The aim of the present study was to investigate the effect of total inhibition of GIP signaling on trabecular bone volume, microarchitecture and quality. We used GIP receptor (GIPR) knockout mice and investigated trabecular bone volume and microarchitecture by microCT and histomorphometry. GIPR-deficient animals at 16 weeks of age presented with a significant (20\%) increase in trabecular bone mass accompanied by an increase (17\%) in trabecular number. In addition, the number of osteoclasts and bone formation rate was significantly reduced and augmented, respectively in these animals when compared with wild-type littermates. These modifications of trabecular bone microarchitecture are linked to a remodeling in the expression pattern of adipokines in the GIPR-deficient mice. On the other hand, despite significant enhancement in bone volume, intrinsic mechanical properties of the bone matrix was reduced as well as the distribution of bone mineral density and the ratio of mature/immature collagen cross-links. Taken together, these results indicate an increase in trabecular bone volume in GIPR KO animals associated with a reduction in bone quality.
\end{abstract}

(c) 2012 Elsevier Inc. All rights reserved.

\section{Introduction}

Bone is a living mineralized material, highly complex and constantly remodeled in mass and architecture to adapt and repair the damages induce by growth, ageing and mechanical stress. In order to maintain a constant bone mass, bone remodeling necessitates a spatio-temporal coupling between osteoclasts, the bone-resorbing cells, and osteoblasts, the bone-forming cells. Bone remodeling is under a complex regulation from various factors that may affect osteoclast and osteoblast physiologies. A role for gastro-intestinal hormones in controlling bone remodeling has been suggested as changes in the profile of serum markers of bone remodeling after a meal coincides with a peak in gastro-intestinal hormones releases [1,2].

Glucose-dependent insulinotropic polypeptide (GIP) is an important gastro-intestinal hormone synthesized and secreted into the blood stream by the duodenal endocrine $\mathrm{K}$ cells after ingestion of a mixed meal [3-5]. To induce a biological response, it binds to glucosedependent insulinotropic polypeptide receptors (GIPRs), expressed

\footnotetext{
* Corresponding author at: GEROM-LHEA UPRES EA 4658, Institut de Biologie en Santé, Université d'Angers, 4 rue Larrey, 49933 Angers Cedex 09, France. Fax: + 33244688451.

E-mail address: guillaume.mabilleau@univ-angers.fr (G. Mabilleau).
}

in the endocrine pancreas, gastrointestinal tract, brain, immune and cardiovascular systems, testis, pituitary, lung, kidney, thyroid, several regions in the central nervous system and adipose tissue [6]. Despite a wide distribution of its receptor in the body, the most remarkable action of GIP is to potentiate glucose-stimulated insulin secretion from pancreatic $\beta$-cells [7]. Recently, the presence of a functional GIPR has been evidenced at the surface of osteoblasts and osteoclasts $[8,9]$. However, the role of GIP in bone physiology remains unclear. In vitro, it seems that GIP stimulates the synthesis of collagen type I and TGF- $\beta$ by osteoblasts $[10,11]$. However, the possible role that GIP might have in controlling bone resorption and/or bone remodeling in vivo is more controversial. Indeed, although Zhong et al., reported that GIP directly reduced osteoclast activity in mature murine osteoclasts in vitro [12], Tsukiyama et al. observed no direct effects of GIP on the same cells [13]. By using a model of GIPR-deficient mice, Tsukiyama et al. described a decrease in trabecular thickness at 8 weeks of age, but this decrease was not observed in 6 -week-old animals. Furthermore, 6 week-old GIPR-deficient mice did not present with a reduction of the trabecular bone volume. However, the number of osteoclasts was augmented at both ages [13]. On the other hand, using the same GIPR-deficient model, Xie et al. described a reduction in trabecular bone volume in younger animals (4-week-old) [14]. This reduction in BV/TV was accompanied by an increase in 
trabecular number with no differences in trabecular thickness and a reduction in trabecular separation [14]. These authors also reported a reduction in bone mineral content in older animals (3- and 5-month old) [14]. From these two studies, the overall conclusion is that the lack of GIPR signaling leads to a decrease, significant or not, in bone mass. More intriguing is the phenotype of GIP-overexpressing mice. In these mice, GIP expression is under the control of a metallothionein promoter and as such the supplementation in zinc led to high circulating GIP levels [15]. Although one could expect a high bone mass, induction of GIP over-expression led to a low bone mass phenotype with a drop in trabecular number [15]. These results support a negative regulation of bone mass under GIP stimulation.

The aims of the present study were to conduct a comprehensive investigation of trabecular bone mass and microarchitecture in GIPR knockout male mice and to assess other parameters of quality of the trabecular bone matrix [16]. Our results indicated that 16-week-old GIPR-deficient male mice present with a significant increase in BV/TV, associated with an increase in trabecular number and a decrease in osteoclast number. Bone quality of the trabecular bone matrix was also reduced in animals lacking a functional GIPR.

\section{Material and methods}

\section{Animals}

Male and female mice presenting a deletion of the GIPR were used in this study. The background and generation of GIPR-deficient mice used in this study has been previously described [17]. Age-matched wildtype (WT) mice with the same C57BL/6 genetic background were used as controls (Harlan Ltd., Oxon, UK). Animals were maintained on a $12 \mathrm{~h}: 12 \mathrm{~h}$ light-dark cycle in a temperature-controlled room $\left(21.5 \pm 1{ }^{\circ} \mathrm{C}\right)$. Animals were individually caged and received food and water ad libitum. All experiments were conducted according to United Kingdom Office regulations (UK Animals Scientific Procedures Act 1986) and European Union laws. Animals were injected intraperitoneally with calcein $(10 \mathrm{mg} / \mathrm{kg})$ seven and two days before necropsy. Blood samples were collected from the cut tip of the tail vein $(\sim 200 \mu \mathrm{l})$ of conscious mice prior to sacrifice by lethal inhalation with $\mathrm{CO}_{2}$ and tibias were then harvested and processed as previously described [18].

\section{Body composition measurements}

Lean and fat percentage were measured by dual energy X-ray absorptiometry using a PIXImus system (Inside Outside Sales, Wisconsin, U.S.A.). The PIXImus system allows accurate measurement of small laboratory animals using a relatively low X-ray energy and ultra high resolution $(0.18 \times 0.18 \mathrm{~mm}$ pixel size $)$. Whole body weight was measured after overnight fasting and the nose-to-tail length was determined.

\section{Intraperitoneal glucose tolerance tests}

Drinking water and a standard rodent maintenance diet (Trouw Nutrition, Cheshire, UK) were freely available until $18 \mathrm{~h}$ before test. Mice received an intraperitoneal injection of glucose alone $(18 \mathrm{mmol} / \mathrm{kg}$ body weight) in a final volume of $8 \mathrm{ml} / \mathrm{kg}$ body weight. Blood samples were collected from the cut tip on the tail vein of conscious mice into chilled fluoride/heparin glucose microcentrifuge tubes (Sarstedt, Nümbrecht, Germany) immediately prior to injection and at 15,30 and 60 min post-injection. Plasma was aliquoted and stored at $-20{ }^{\circ} \mathrm{C}$ prior to glucose determination. Plasma glucose and insulin were assayed by an automated glucose oxidase procedure using a Beckman Glucose Analyzer II (Beckman Instruments, Galway, Ireland) and a modified dextran-coated charcoal radioimmunoassay [19], respectively.

\section{$X$-ray microcomputed tomography}

MicroCT analysis was performed with a Skyscan 1172 microtomograph (Skyscan, Kontich, Belgium) equipped with an X-ray tube working at $69 \mathrm{kV} / 100 \mu \mathrm{A}$. The pixel size was fixed at $3.75 \mu \mathrm{m}$, the rotation step at $0.25^{\circ}$ and exposure was done with a $0.5-\mathrm{mm}$ aluminum filter. Bone mass and microarchitecture at the tibia metaphysis were determined with the CTan software (release 1.11.4.2, Skyscan). The volume of interest (VOI) was located $0.5 \mathrm{~mm}$ below the growth plate on a height of $2 \mathrm{~mm}$ (534 sections). Trabecular bone volume (BV/TV $3 \mathrm{D}$, in $\%$ ), trabecular thickness (Tb.Th ${ }_{3 \mathrm{D}}$, in $\mu \mathrm{m}$ ), trabecular number (Tb.N, in $1 / \mu \mathrm{m})$, trabecular separation (Tb.Sp, in $\mu \mathrm{m})$, trabecular pattern factor (Tb. $\mathrm{P}_{\mathrm{f}}$ ) and structure model index (SMI) were measured according to guidelines and nomenclature proposed by the American Society for Bone and Mineral Research [20].

\section{Bone histomorphometry}

Bone samples were embedded, undecalcified in poly (methylmethacrylate) (pMMA) at $4{ }^{\circ} \mathrm{C}$ to preserve enzyme activities. Sections ( $7-\mu \mathrm{m}$ thickness) were performed on a heavy duty microtome equipped with a $50^{\circ}$ tungsten carbide knife. For each animal, four non serial sections ( $\sim 50 \mu \mathrm{m}$ apart) were left unstained for the measurement of calcein-based parameters (original magnification $\times 400$ ), four sections were stained with Goldner's trichrome for two-dimensional bone volume and marrow adiposity measurements (original magnification $\times 40$ ), four sections were stained with toluidine blue for osteoblast counting (original magnification $\times 400$ ) and four additional sections were stained for the osteoclastic tartrate resistant acid phosphatase (TRAcP). TRAcP identification is based on a histoenzymatic detection with a simultaneous azo-dye coupling method, bone being counterstained with phosphomolybdic aniline blue and was performed at an original magnification of $\times 200$ [21]. Only TRACP-positive nucleated cells in contact with bone were counted as osteoclasts. The region of interest (ROI) was located in the secondary spongiosa $0.5 \mathrm{~mm}$ below the growth plate on a height of $2 \mathrm{~mm}$. Standard bone histomorphometrical nomenclatures, symbol and units were used as described in the report of the American Society for Bone and Mineral Research [22].

\section{Ex vivo cell culture}

Bone marrow cells were isolated from the long bones of 16 weeks-old male animals by flushing tibias and femurs with alpha-MEM as previously reported [23]. For osteoblast differentiation, bone marrow cells were plated into a $25 \mathrm{~cm}^{2}$ culture flask until confluency ( 3 days). At confluency, cells were detached with trypsin $1 \%$ and seeded into a 24 -well tissue plate at a density of $2.5 \times 10^{4}$ cells/well in alpha-MEM supplemented with $10 \%$ fetal calf serum, $2 \mathrm{mM}$ L-glutamine, $100 \mathrm{U} / \mathrm{ml}$ penicillin, $100 \mu \mathrm{g} / \mathrm{ml}$ streptomycin, $5 \mathrm{mM} \beta$-glycerophosphate and $50 \mu \mathrm{g} / \mathrm{ml}$ ascorbic acid. For osteoclast culture, bone marrow cells were cultured for $24 \mathrm{~h}$ into a $25 \mathrm{~cm}^{2}$ flask in alpha-MEM supplemented with $10 \%$ fetal calf serum, $2 \mathrm{mM} \mathrm{L-glutamine,} 100 \mathrm{U} / \mathrm{ml}$ penicillin and $100 \mu \mathrm{g} / \mathrm{ml}$ streptomycin to allow stromal cells attachment. Non adherent cells were then collected and plated in 24 well-plate in alpha-MEM supplemented with $10 \%$ fetal calf serum, $2 \mathrm{mM}$ L-glutamine, $100 \mathrm{U} / \mathrm{ml}$ penicillin, $100 \mu \mathrm{g} / \mathrm{ml}$ streptomycin, $25 \mathrm{ng} / \mathrm{ml}$ macrophage-colony stimulating factor (M-CSF-R\&D systems, Abingdon, UK) and $50 \mathrm{ng} / \mathrm{ml}$ soluble RANKL (Peprotech Ltd, London, UK). After seven days of culture, TRAcP staining was performed as previously described [24]. TRAcP-positive cells with more than three nuclei were considered as osteoclasts.

\section{Gene expression}

Total RNA was extracted from osteoblast or osteoclast ex vivo cultures using TriZol, reversed transcribed using iScript cDNA synthesis kit (Bio-Rad) and amplified by real-time PCR using SYBR GREEN PCR 
master mix (Bio-Rad). Primer sequences are presented in Supplemental Table 1 . The expression level of each sample was normalized against gapdh mRNA expression.

\section{Serum levels of soluble mediators}

Levels of adipokines were determined using the mouse adipokine profiler array (R\&D Systems Europe, Abingdon, UK) according to the manufacturer recommendations. Image analysis with Image J $1.45 \mathrm{~s}$ was performed to quantify the relative expression of the different mediators of the array. Serum levels of c-terminal telopeptide of collagen type I (CTX-I) and osteocalcin were assessed with commercially available kit (Ratlaps®-Immunodiagnostic systems and mouse osteocalcin kit-Immutopics, respectively). Serum vanillylmandelic acid was assayed with a commercially-available kit (CusaBio Biotech, Wuhan, China) according to the manufacturer recommendations.

\section{Quantitative backscattered electron imaging ( $q B E I)$}

Quantitative backscattered electron imaging was employed to determine the bone mineral density distribution (BMDD) according to the methodology described by Roschger et al. [25]. Poly (methylmethacrylate) blocks used for bone histomorphometry were polished to a 1- $\mu \mathrm{m}$ finish with diamond particles, carbon-coated and observed with a scanning electron microscope (EVO LS10, Carl Zeiss Ltd, Nanterre, France) equipped with a five quadrant semi-conductor backscattered electron detector. The microscope was operated at $20 \mathrm{keV}$ with a probe current of $250 \mathrm{pA}$ and a working distance of $15 \mathrm{~mm}$. The backscattered signal was calibrated using pure carbon $(Z=6$, mean gray level $=25)$, pure aluminum $(Z=13$, mean gray level $=225)$ and pure silicon $(Z=14$, mean gray level $=253)$ standards (Micro-analysis Consultants Ltd, St Ives, UK). For these contrast/brightness settings, the BSE gray level histogram was converted into weight percentage of calcium as described in Roschger et al. Eventual changes in brightness and contrast due to instrument instabilities were checked by monitoring the current probe and imaging the reference material $(\mathrm{C}$, $\mathrm{Al}$ and $\mathrm{Si}$ ) every $15 \mathrm{~min}$. The trabecular bone areas were imaged $0.5 \mathrm{~mm}$ below the growth plate at a $200 \times$ nominal magnification, corresponding to a pixel size of $0.5 \mu \mathrm{m}$ per pixel. The gray level distribution of each image was analyzed with a lab-made routine using Image J. Three variables were obtained from the bone mineral density distribution: $\mathrm{Ca}_{\text {peak }}$ is the most frequently observed calcium concentration, $\mathrm{Ca}_{\text {mean }}$ is the average calcium concentration and $\mathrm{Ca}_{\text {width }}$ is the width of the histogram at half maximum of the peak.

\section{Nanoindentation}

Nanoindentation tests evaluated the intrinsic mechanical properties of the bone matrix. As nanoindentation assesses volume of material at a length scale less than that of individual microstructural features in bone, this technique avoids confounding factors such as microstructure and porosity that affect tissue properties at larger length scales. Tests were performed on the same sample used for qBEI measurements. Briefly, mechanical tests included five indents positioned in trabeculae in the secondary spongiosa with a NHT-TTX system (CSM, Peseux, Switzerland) equipped with a Berkowitch diamond probe. The indents were done up to a depth of $900 \mathrm{~nm}$ with a loading/unloading rate of $40 \mathrm{mN} / \mathrm{min}$. At maximum load, a holding period of $15 \mathrm{~s}$ was applied to avoid creeping of the bone material. Maximum load, indentation modulus, hardness and dissipated energy were determined according to Oliver and Pharr [26]. Briefly, maximum load corresponds to the load reached at maximum penetration. Indentation modulus is defined by the initial slope of the unloading section of the curve whereas hardness is interpreted as the mean pressure the material can resist and is calculated as the ratio of maximum load to contact area. Dissipated energy corresponds to the area delimited by the loading and unloading curves.

\section{Fourier transformed infrared microspectroscopy (FTIRM)}

Sections of $4 \mu \mathrm{m}$ thickness were cut dry on a heavy duty microtome equipped with tungsten carbide knives (Leica Polycut S) and sandwiched between $\mathrm{BaF}_{2}$ optical windows. Spectral analysis were obtained on a Bruker Vertex 70 spectrometer (Brukers optics, Ettlingen, Germany) interfaced with a Bruker Hyperion 3000 infrared microscope equipped with a standard single element Mercury Cadmium Telluride (MCT) detector. Infrared spectra were recorded at a resolution of $4 \mathrm{~cm}^{-1}$, with an average of 32 scans in transmission mode. Background spectral images were collected under identical conditions from the same $\mathrm{BaF}_{2}$ windows at the beginning and end of each experiment to ensure instrument stability. For FTIRM analysis, spectra were acquired on three different trabeculae per section with an area of $45 \times 45 \mu \mathrm{m}$ each and analyzed with the Opus Software (release 6.5, Bruker). Four sections per animal were analyzed. Sequential raw spectra for each trabecula were averaged and the contribution of the embedding PMMA and water vapor were corrected prior to baseline correction. The evaluated IR spectral parameters were (1) mineral crystallinity, which reflects the apatite size and perfection, calculated as the ratio of the relative intensity of subbands at 1020 and $1030 \mathrm{~cm}^{-1}$ of the phosphate band [27]; (2) collagen maturity, determined as the relative ratio of pyridinium trivalent (Pyr, mature collagen) to dehydrodihydroxylysinonorleucine divalent (deH-DHLNL, new collagen) collagen cross-links using their respective subbands located at $1660 \mathrm{~cm}^{-1}$ and $1690 \mathrm{~cm}^{-1}$ of the amide I peak [28] and (3) carbonates to phosphates ratio, which reflects the carbonate content in bone and determined by the ratio of integrated areas of the $v 2 \mathrm{CO}_{3}^{2-}$ region $\left(850-890 \mathrm{~cm}^{-1}\right)$ to the $v 1, v 3$ phosphate band $\left(900-1200 \mathrm{~cm}^{-1}\right)$ [29].

\section{Statistical analysis}

Results were expressed as mean \pm standard error of the mean (SEM). Non-parametric Mann-Whitney $U$-test was used to compare the differences between the groups using the Systat statistical software release 13.0 (Systat software Inc., San José, CA). Differences at $\mathrm{p}<0.05$ were considered significant. Correlation between serum levels of adipokines and $\mathrm{BV} / \mathrm{TV}_{3 \mathrm{D}}$ was assessed by a least squares linear regression analysis.

\section{Results}

GIPR KO mice exhibit lower body mass and lower fat mass

The growth curve indicated that male GIPR-deficient animals presented at 16 weeks of age with a significant $11 \%$ reduction in body mass ( $p=0.027$ ) (Fig. 1A). Furthermore, in terms of body composition, as compared with WT animals, GIPR deficient mice at 16 weeks of age presented with a significant $27 \%$ decrease in fat mass $(p=$ 0.027 ) (Fig. 1B). No differences in nose-to-tail length were observed between WT and GIPR deficient animals at 16 weeks of age (Fig. 1C). Although blood glucose appeared slightly increased in GIPR deficient animals, no significant differences were observed in this parameter (Fig. 1D) nor in insulin levels (Fig. 1E).

\section{GIPR KO mice have a higher trabecular bone volume}

As body weight lag behind in 16 weeks old GIPR-deficient animals, trabecular bone volume was determined by high resolution microCT at this age. As represented Fig. 2, the trabecular bone volume appeared to be increased in male GIPR-deficient animals. Indeed, as compared to WT animals, male GIPR deficient mice presented a significant $20 \%$ 
A

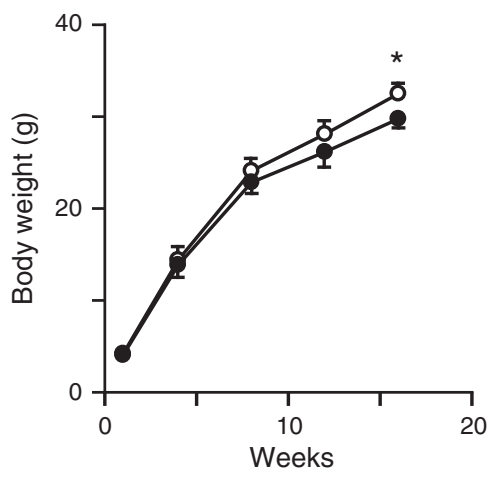

D
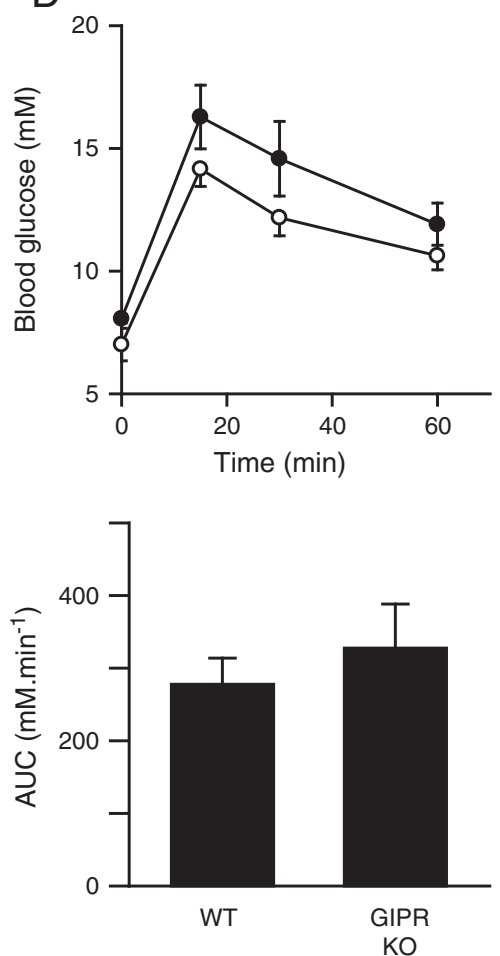

$\mathrm{B}$

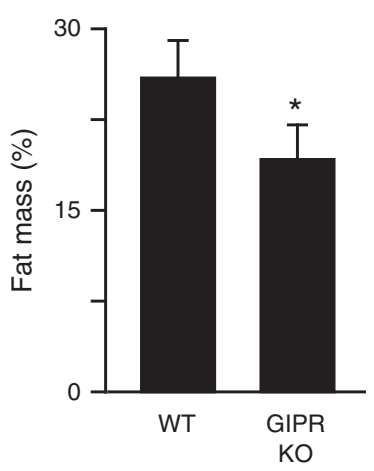

C

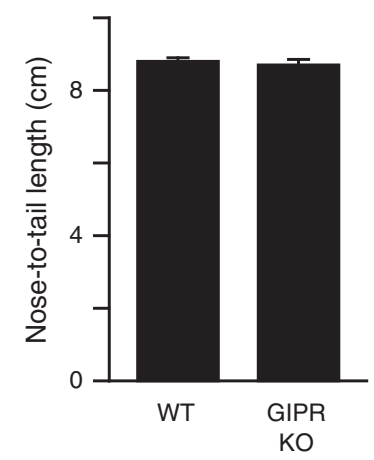

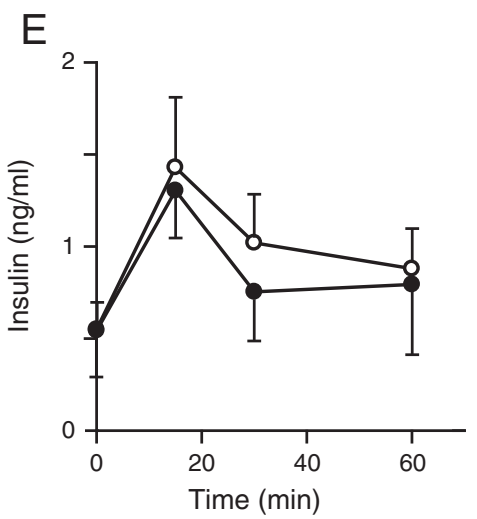

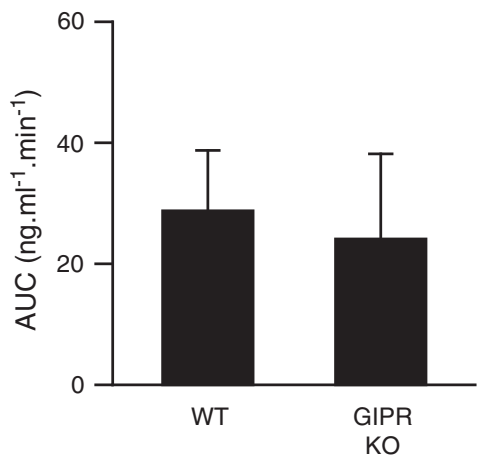

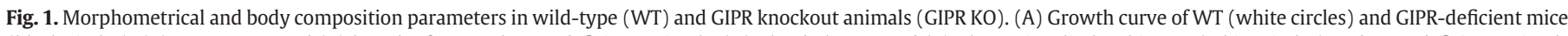

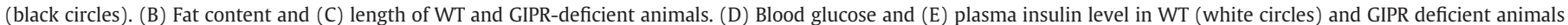
(black circles). *: $\mathrm{p}<0.05$ vs. WT. $\mathrm{N}=4-7$ in each group.

increase in $\mathrm{BV} / \mathrm{TV}_{3 \mathrm{D}}(\mathrm{p}=0.008$; Table 1$)$. This increase in trabecular bone volume was accompanied by a significant $17 \%$ augmentation in trabecular numbers $(\mathrm{p}=0.006)$ and a $18 \%$ decrease in trabecular separation $(p<0.001)$ in GIPR KO animals. On the other hand, the trabecular thickness was unchanged between WT and GIPR deficient animals $(\mathrm{p}=0.72)$. Although slight decreases in Tb.P $P_{\mathrm{f}}$ and SMI were observed, they did not reach significance. In order to assess whether these differences were gender-related, we also investigated the trabecular microarchitecture in female GIPR-deficient animals (Table 1). Here again, deficient animals presented with a significant $40 \%$ augmentation in $\mathrm{BV} / \mathrm{TV}_{3 \mathrm{D}}$, associated with a $26 \%$ increase in Tb.N and a $14 \%$ decrease in Tb.Sp (Table 1).

GIPR KO mice exhibit a decrease in osteoclast number and increase in osteoblast activity

In order to confirm the higher trabecular bone volume in GIPR deficient animals, we determined trabecular bone volume by histomorphometry in male (Fig. 3) and female (Fig. 4). Again, we found a $24 \%$ augmentation in trabecular bone volume in male GIPR deficient animals $(p=0.038)$. The number of osteoclast per bone perimeter was reduced in male GIPR deficient animals by $20 \%$ ( $p=0.042$ ). On the other hand, in GIPR deficient animals, the number of osteoblasts was significantly augmented and accompanied by a significant $80 \%$ increase in mineral apposition rate (Cn.MAR) and a $440 \%$ augmentation in bone formation rate (Cn.BFR/BS) $(1.7 \pm 0.3$ vs. $3.0 \pm 0.4 ; \mathrm{p}=0.018$ and $0.29 \pm 0.02$ vs. $1.56 \pm 0.69 ; \mathrm{p}=0.021)$. As compared with WT animals, serum levels of CTX were significantly reduced by $21.5 \%$ in male GIPR-deficient animals $(p=0.003)$. On the other hand, despite an increase in serum osteocalcin in male GIPRdeficient animals, this parameter did not reach statistical significance $(\mathrm{p}=0.113)$. In female deficient animals, the number of osteoclasts was also significantly decreased by $39 \%(p=0.021)$ and the number of osteoblasts significantly increased by $88 \%(\mathrm{p}=0.025)$. Although no differences were observed in Cn.MAR between female WT and GIPR-deficient mice, mineralized surface and bone formation rate were increased significantly by $55 \%(p=0.012)$ and $55 \%(p=0.019)$ respectively. 


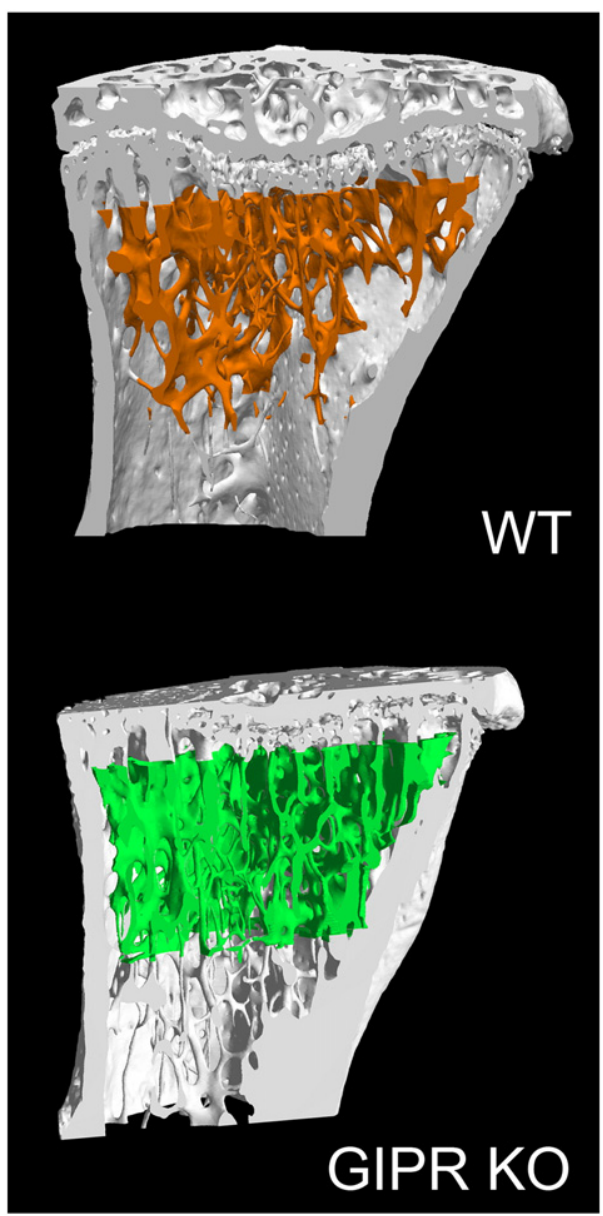

Fig. 2. Three-D models of the tibia proximal metaphysis in wild-type (WT) and GIPR knockout (GIPR KO) animals. Trabecular regions of interest have been colorized.

\section{Trabecular bone microarchitecture is also altered in old animals}

As body weight is significantly reduced in 16 weeks-old animals, we determined trabecular microarchitecture parameters in younger (8-weeks old) and older (45-weeks old) male animals. In young animals, trabecular microarchitecture as assessed by high resolution microCT did not seem affected by the lack of a functional GIPR (Table 2). However, despite no alteration in the microarchitecture, the number of osteoclasts was significantly reduced by $24 \%$ in these animals $(p=0.025$, Supplemental Fig. S1). Also in these animals, as compared with WT animals, the mineralized surface and bone formation rate were significantly increased $(\mathrm{p}=0.012$ and $\mathrm{p}=0.009$ respectively).
In older animals, the trabecular alterations observed at 16 weeks of age were exacerbated at 45 weeks of age (Table 2) in GIPR deficient animals as compared with WT. However, in these animals, despite a decrease in the number of osteoclasts, this parameter did not reach significance $(p=0.465)$. In the other hand, the number of osteoblasts and marrow adiposity were significantly increased $(p=0.028$ and $\mathrm{p}=0.047$ respectively) as compared with WT (Supplemental Fig. S2).

Osteoblast and osteoclast differentiation markers are affected in GIPR-deficient animals

In order to evaluate whether bone cell differentiation was impaired in GIPR-deficient mice, we performed ex vivo cultures of osteoclast and osteoblast precursors (Fig. 5). Although the number of newly-generated osteoclasts was reduced in ex vivo cultures of GIPR-deficient mice, this difference did not reach significance $(p=0.127)$. The number of alkaline phosphatase positive cells and the extent of mineralization were augmented in ex vivo cultures of GIPR-deficient mice. However, these two parameters also did not reach significance $(p=0.275$ and $p=0.127$, respectively). The gene expression profile in osteoblast cultures revealed significant augmentations in runx2, osteocalcin and collagen type I alpha I genes $(p=0.05, p=0.05$ and $p=0.05$ respectively). On the other hand, expression of atf4 and RANKL genes was significantly decreased ( $\mathrm{p}=0.05$ and $\mathrm{p}=0.05$ respectively). The gene expression pattern observed in osteoclast cultures revealed a significant decrease in nfat 2 , rank and trap gene expression $(p=0.05$, $\mathrm{p}=0.05$ and $\mathrm{p}=0.05$ respectively).

\section{Adipokine profile is modified in GIPR-deficient animals}

As reported above, GIPR KO mice presented a reduction in fat mass. As such, we aimed to determine the profile of adipokines known to affect bone remodeling. Serum levels of circulating leptin, resistin and adiponectin were determined in male animals (Fig. 6). Resistin levels were not significantly different between GIPR KO and WT animals $(p=0.248)$. On the other hand, serum levels of leptin were significantly decreased $(\mathrm{p}=0.02)$ whilst adiponectin was significantly increased $(p=0.043)$ in GIPR-deficient animals as compared with WT. A regression analysis between adipokine levels and BV/TV $3 \mathrm{D}$ was performed to estimate a possible role of adiponectin and leptin in the observed skeletal phenotype. Serum adiponectin levels and trabecular bone volume were positively correlated with a correlation coefficient of $0.70(p=0.043)$. Serum leptin levels and trabecular bone volume were inversely correlated with a correlation coefficient of $-0.72(p=0.017)$.

As leptin has been shown to alter bone remodeling through a hypothalamic relay and activation of the sympathetic nervous system, we thought to determine the serum levels of vanillylmandelic acid (VMA), a degradation products of catecholamine. Despite a decrease in serum leptin level, the serum levels of VMA were reduced in GIPR-deficient animals as compared with WT but did not reach

Table 1

Trabecular microarchitecture in WT and GIPR KO mice at 16 weeks of age.

\begin{tabular}{|c|c|c|c|c|c|c|}
\hline & \multicolumn{3}{|l|}{ Male } & \multicolumn{3}{|l|}{ Female } \\
\hline & $\begin{array}{l}\text { WT } \\
(n=11)\end{array}$ & $\begin{array}{l}\text { GIPR KO } \\
(\mathrm{n}=12)\end{array}$ & $\mathrm{p}$ value & $\begin{array}{l}\text { WT } \\
(n=6)\end{array}$ & $\begin{array}{l}\text { GIPR KO } \\
(n=5)\end{array}$ & $\mathrm{p}$ value \\
\hline $\mathrm{BV} / \mathrm{TV}_{3 \mathrm{D}}(\%)$ & $12.4 \pm 0.6$ & $14.9 \pm 0.4^{* *}$ & 0.008 & $4.5 \pm 0.3$ & $6.3 \pm 0.6^{*}$ & 0.021 \\
\hline Tb.Th $(\mu \mathrm{m})$ & $55.3 \pm 1.4$ & $54.7 \pm 0.6$ & 0.72 & $60.9 \pm 1.5$ & $64.4 \pm 2.0$ & 0.386 \\
\hline Tb.N $(1 / \mathrm{mm})$ & $2.3 \pm 0.1$ & $2.7 \pm 0.1^{* *}$ & 0.006 & $0.7 \pm 0.1$ & $1.0 \pm 0.1^{*}$ & 0.043 \\
\hline Tb.Sp $(\mu \mathrm{m})$ & $268 \pm 5$ & $220 \pm 5^{* *}$ & $<0.001$ & $493 \pm 13$ & $422 \pm 20^{*}$ & 0.043 \\
\hline Tb.P. & $0.0175 \pm 0.0006$ & $0.0164 \pm 0.0011$ & 0.389 & $0.03 \pm 0.0017$ & $0.02 \pm 0.001$ & 0.248 \\
\hline SMI & $1.72 \pm 0.04$ & $1.66 \pm 0.08$ & 0.559 & $2.42 \pm 0.1$ & $2.39 \pm 0.04$ & 0.773 \\
\hline
\end{tabular}

* $\mathrm{p}<0.05$ vs. WT animals.

** $\mathrm{p}<0.01$ vs. WT animals. 
A
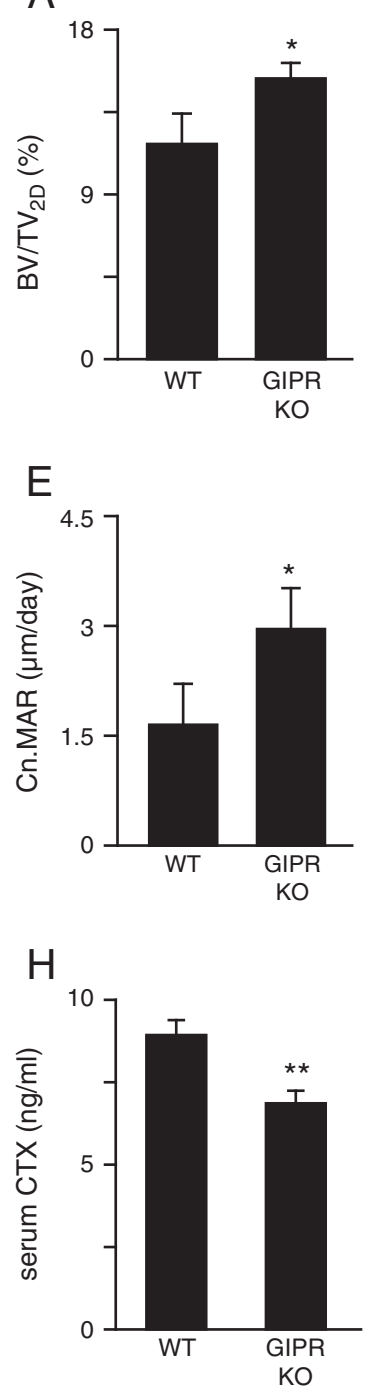

B

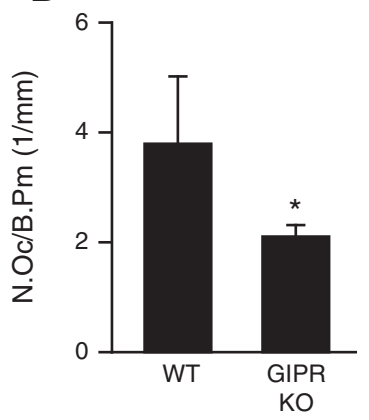

$\mathrm{F}$
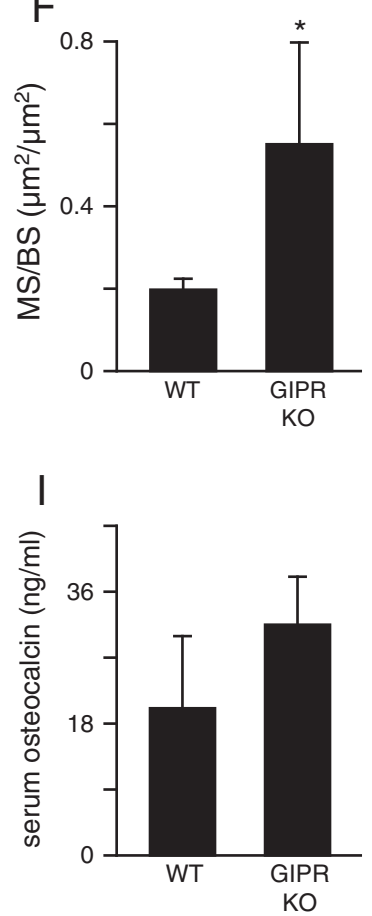

C
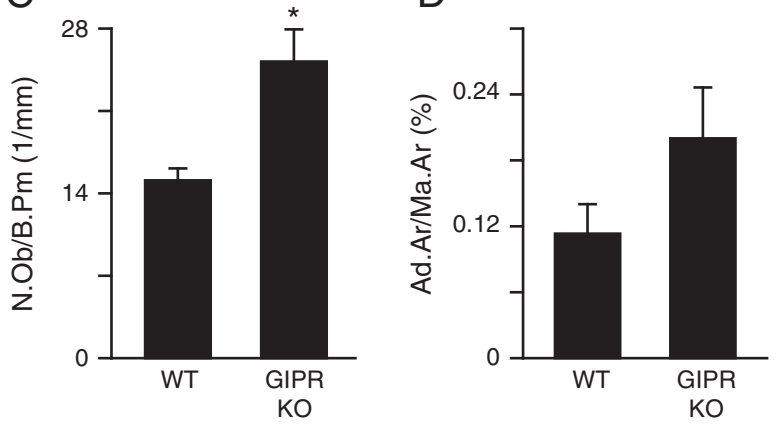

G

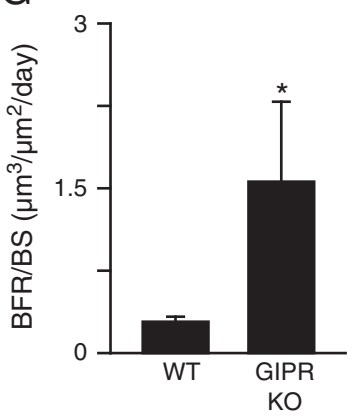

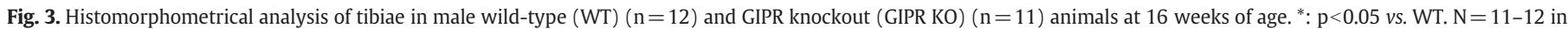
each group.

significance ( $p=0.064$, Fig. 6 ). We also thought to determine the expression of ucp2 in bone marrow. Ucp2 expression is tightly regulated by the sympathetic nervous system. Here again, although ucp2 seemed decreased in GIPR-deficient animals, this parameter did not reach significance $(\mathrm{p}=0.275)$.

Intrinsic bone tissue quality is decreased in trabecular bone of GIPR KO mice

The intrinsic mechanical properties of the trabecular network were investigated by nanoindentation. Clearly, GIPR-deficient animals exhibited a reduction in intrinsic bone strength as evidenced by significant lower values for the maximum load, indentation modulus and dissipated energy (Table 3). On qBEI analysis, the bone mineral distribution in the trabecular bone tissue was shifted to the left in GIPR KO mice as compared to WT animals (Fig. 7), suggesting a lower mineralization profile in these animals. Indeed, $\mathrm{Ca}_{\text {peak }}$ was significantly reduced GIPR KO animals $(23.11 \% \pm 0.52$ vs. $24.71 \% \pm 0.42 ; \mathrm{p}=0.028)$ (Table 3 ). Furthermore, $\mathrm{Ca}_{\text {mean }}$ was significantly decreased in GIPR-deficient animals $(22.20 \% \pm 0.88$ vs. $23.78 \% \pm 0.29 ; \mathrm{p}=0.018)$. Although $\mathrm{Ca}_{\text {width }}$ was slightly lower in deficient animals, this parameter did not reach significance as compared with WT $(2.88 \pm 0.21$ vs. $3.45 \pm 0.49 ; \mathrm{p}=0.078)$.
Moreover, the Pyr/deH-DHLNL ratio was significantly lower in GIPRdeficient animals as compared with wild type (Table 3). On the other hand, no differences were observed neither in the crystallinity nor carbonate substitution of the mineral.

\section{Discussion}

Bone remodeling is a complex process subjected to regulation from various molecules. The concept of control of bone mass and remodeling by the gastro-intestinal tract has emerged in the last decade. Recently, a role for gut-derived serotonin in the control of bone remodeling has been evidenced [30,31] as well as a link between glucagon-like peptide-2 and bone resorption [2]. In the present study, the role of GIP, a gut peptide, in controlling bone mass and microarchitecture was investigated. By using a model of GIPR deficiency, we evidenced a significant increase in trabecular bone volume associated with an augmentation in trabecular number. This increase in trabecular bone volume was also accompanied by a reduction in the number of trabecular osteoclast and an increase in osteoblast activity as evidenced by increased bone formation rate in male and female. At 45 weeks of age, GIPR KO male mice presented with an extreme increase in trabecular bone volume as compared with WT control mice. Ex vivo cultures of 
A

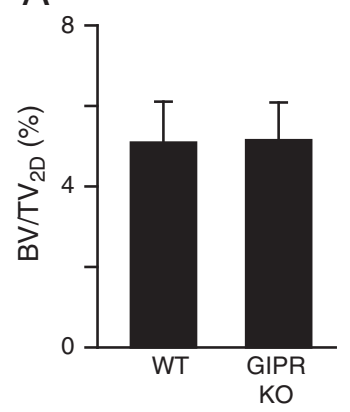

$\mathrm{E}$

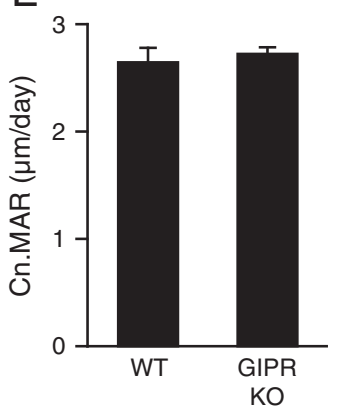

B

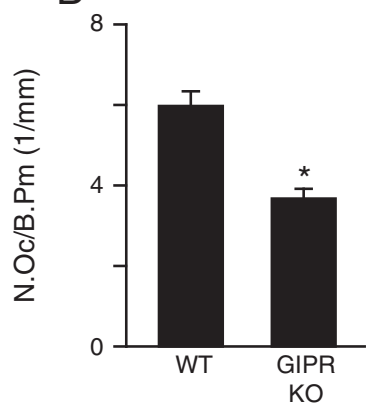

$\mathrm{F}$

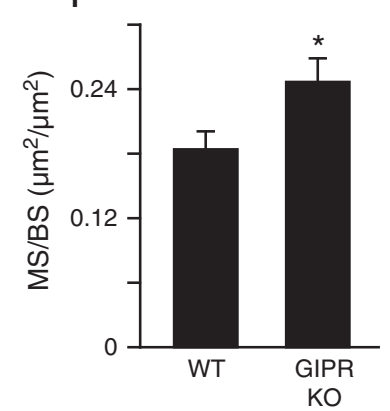

C

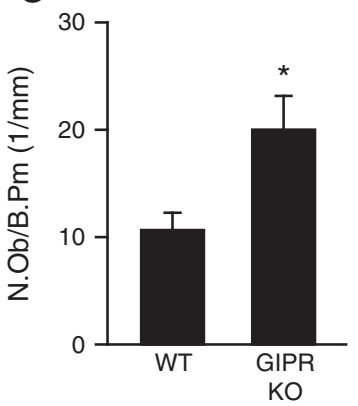

$\mathrm{D}$

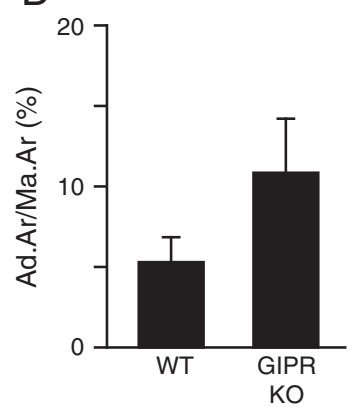

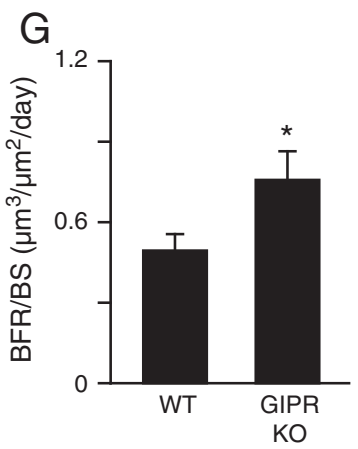

Fig. 4. Histomorphometrical analysis of tibiae in female wild-type (WT) and GIPR knockout (GIPR KO) animals at 16 weeks of age. *: p<0.05 vs. WT. N=5-6 in each group.

WT and GIPR KO bone cells highlighted that cell differentiation might be affected in deficient animals. Indeed, although it did not reach significance, osteoclast precursors transformed into osteoclast at a lower rate in deficient animals whilst osteoblast differentiation seemed to increase. The pattern of gene expression in these two cell population also support these findings. Taken together, these results suggest a negative effect of GIP/GIPR signaling on bone remodeling.

Previous studies performed by Xie et al. and Tsukiyama et al. showed either a decrease of trabecular thickness or a decrease of trabecular bone volume in mice lacking a functional GIPR. It is worth noting that these two studies, although performed on GIPR-deficient mice, have been undertaken with a different genetic construction. In human, the gipr gene is composed of 14 exons whilst in rats and mice, the gipr comprised 15 exons leading to several forms of this receptor by alternative splicing [32]. The functional GIPR, independent of the species, is a G protein-coupled receptor belonging to the B1 subfamily which encompasses receptors for other hormones, including glucagonlike peptide-1, vasoactive intestinal peptide, parathyroid hormone and calcitonin [33]. Members of this family are composed of a large extracellular $\mathrm{N}$ terminus, a serpentine domain with seven transmembrane helices and a short intracellular C terminus [34]. GIP interacts with its receptor by binding to the extracellular domain. The GIPR deficient model used by Xie et al. and Tsukiyama et al. possessed a deletion of exons 4 and 5 that encode a portion, but not the totality, of the extracellular domain of the GIPR. Our model of GIPR deficiency consists of a deletion of the first 6 exons, which encode the totality of the extracellular domain and a portion of the first transmembrane helix of the GIPR $[35,36]$. Although both constructs resulted in non-functional receptors as assessed by cAMP responses, one might argue that the binding affinity of GIP to its receptor might be different between the two constructs and as such the availability of GIP for another splice variant of the receptor might be impaired.

Surprisingly, the percentage of fat mass and the number of osteoclast were decreased in our GIPR-/-mice. This is in contradiction of what was observed in previous studies were these two parameters were increased $[13,14]$. Connections between fat and bone metabolism have been evidenced, with a role for adipokines in controlling bone remodeling. Adiponectin controls bone formation through paracrine and endocrine pathways [37]. Through a paracrine manner, adiponectin increases osteogenesis whilst circulating levels of adiponectin have been linked to indirectly enhancing insulin signaling in osteoblasts and as such increasing bone formation. The mode of action of leptin, another adipokine, on bone remodeling remains unclear. Most of the literature supports the idea that leptin suppresses bone mass by acting in the brainstem to reduce serotonin-dependent sympathetic signaling from the ventromedial hypothalamus to bone. Osteoblasts appear to be a target of this central regulation and lead to reduced bone formation and increased expression of RANKL that promotes osteoclast

Table 2

Trabecular microarchitecture in male WT and GIPR KO mice at 8 weeks and 45 weeks of age.

\begin{tabular}{|c|c|c|c|c|c|c|}
\hline & \multicolumn{3}{|l|}{8 weeks old } & \multicolumn{3}{|l|}{45 weeks old } \\
\hline & $\begin{array}{l}\text { WT } \\
(n=6)\end{array}$ & $\begin{array}{l}\text { GIPR KO } \\
(n=6)\end{array}$ & $\mathrm{p}$ value & $\begin{array}{l}\text { WT } \\
(n=6)\end{array}$ & $\begin{array}{l}\text { GIPR KO } \\
(n=6)\end{array}$ & $\mathrm{p}$ value \\
\hline $\mathrm{BV} / \mathrm{TV}_{3 \mathrm{D}}(\%)$ & $13.0 \pm 1.0$ & $12.2 \pm 1.2$ & 0.239 & $4.7 \pm 0.5$ & $10.1 \pm 0.5^{\text {** }}$ & $<0.001$ \\
\hline Tb.Th $(\mu \mathrm{m})$ & $52.7 \pm 2.2$ & $50.8 \pm 1.0$ & 0.243 & $62.9 \pm 1.7$ & $69.7 \pm 1.6^{*}$ & 0.018 \\
\hline Tb.N $(1 / \mathrm{mm})$ & $2.6 \pm 0.2$ & $2.3 \pm 0.2$ & 0.368 & $0.8 \pm 0.1$ & $1.5 \pm 0.1^{* *}$ & $<0.001$ \\
\hline Tb.Sp $(\mu \mathrm{m})$ & $226 \pm 9$ & $260 \pm 21$ & 0.160 & $445 \pm 29$ & $325 \pm 4^{* *}$ & 0.004 \\
\hline Tb. $P_{f}$ & $0.0212 \pm 0.0016$ & $0.0225 \pm 0.0006$ & 0.469 & $0.0255 \pm 0.0007$ & $0.0185 \pm 0.0009^{* *}$ & $<0.001$ \\
\hline SMI & $1.95 \pm 0.08$ & $2.00 \pm 0.04$ & 0.572 & $2.50 \pm 0.02$ & $2.21 \pm 0.06^{* *}$ & 0.001 \\
\hline
\end{tabular}

\footnotetext{
* $\mathrm{p}<0.05$ vs. WT animals.
}

** $\mathrm{p}<0.01$ vs. WT animals. 
A

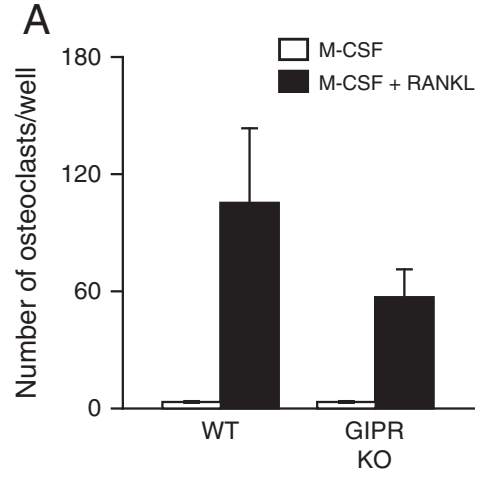

D

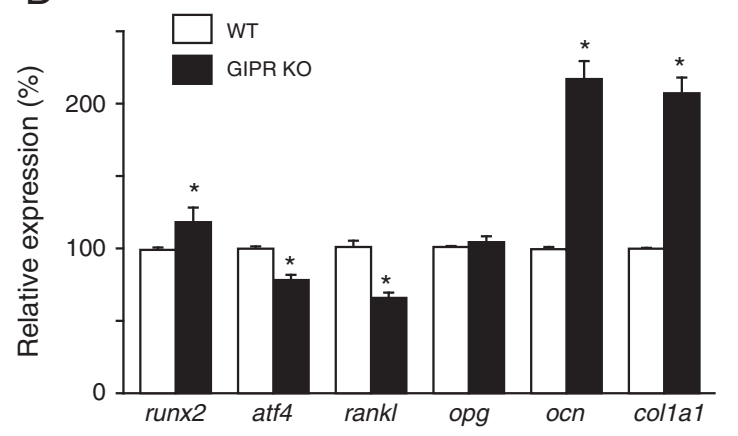

$\mathrm{B}$

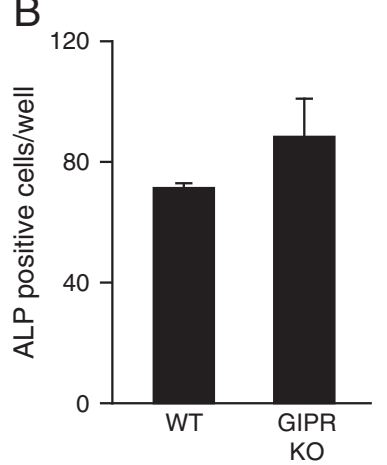

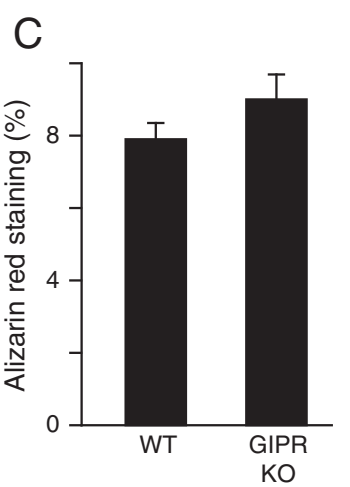

E

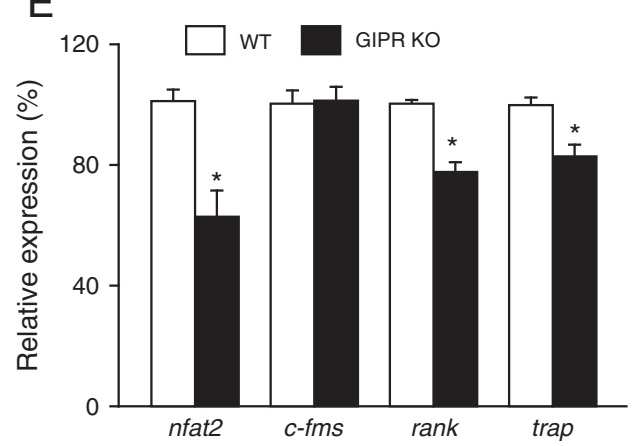

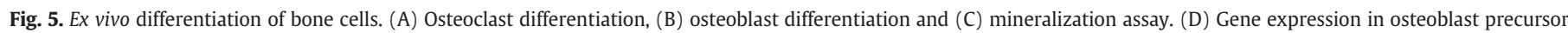
cells and (E) gene expression in osteoclast precursor cells. ${ }^{*}$ : $\mathrm{p}<0.05 v s$. WT. $\mathrm{N}=3$ in each group.

differentiation and bone resorption [38,39]. In our study, a relatively strong correlation has been established between increased adiponectin and reduced leptin levels, and increased trabecular bone volume indicating that the modifications of adipokine profile in GIPR-deficient animals could result in the observed bone phenotype. One could argue that although serum levels of VMA as well as ucp2 expression were reduced in deficient animals, these two parameters did not reach statistical significance. Nevertheless, it does not rule out a role
A

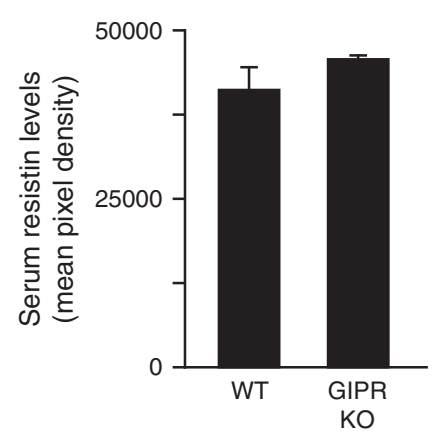

$\mathrm{D}$

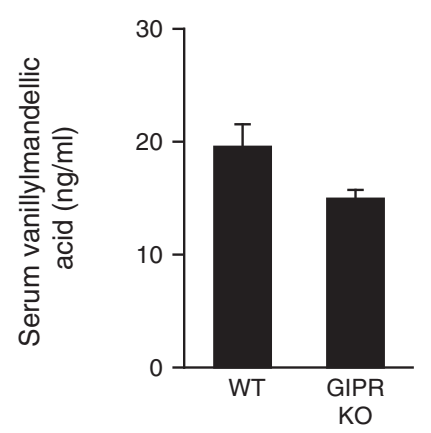

B

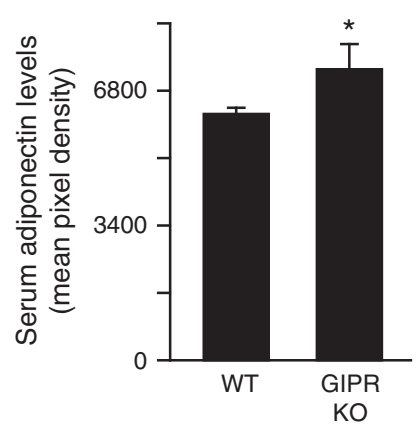

E

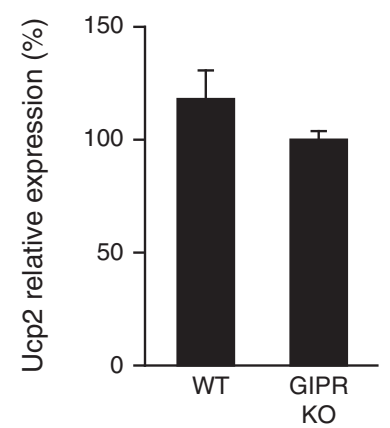

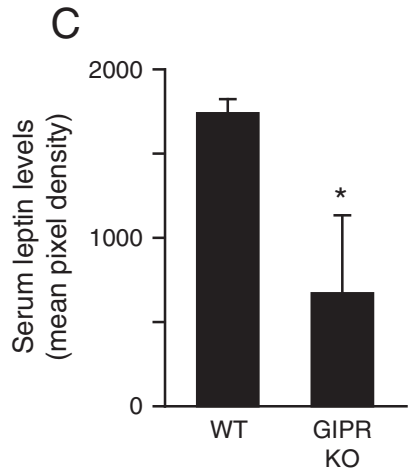

Fig. 6. Serum adipokine levels in male wild-type (WT) and GIPR knockout (GIPR KO) animals at 16 weeks of age. *: p<0.05 vs. WT. N=4-7 in each group. 
Table 3

Bone quality analysis in male WT and GIPR KO mice at 16-weeks of age.

\begin{tabular}{lccc}
\hline & $\begin{array}{l}\text { WT } \\
(\mathrm{n}=11)\end{array}$ & $\begin{array}{l}\text { GIPR KO } \\
(\mathrm{n}=12)\end{array}$ & p value \\
\hline Intrinsic tissue properties & & & \\
Maximum load (mN) & $15.3 \pm 0.6$ & $13.9 \pm 0.1^{*}$ & 0.027 \\
Hardness (MPa) & $889.1 \pm 39.7$ & $822.4 \pm 12$ & 0.074 \\
Indentation modulus (GPa) & $15.6 \pm 0.1$ & $13.1 \pm 0.3^{*}$ & 0.018 \\
Dissipated energy (mN nm) & $4189.9 \pm 60.8$ & $3665.0 \pm 36.0^{*}$ & 0.014 \\
& & & \\
Bone mineralization parameters & & & \\
Ca $a_{\text {peak }}$ \% weight) & $24.7 \pm 0.4$ & $23.1 \pm 0.5^{*}$ & 0.028 \\
Ca mean (\% weight) & $23.8 \pm 0.3$ & $22.2 \pm 0.8^{*}$ & 0.018 \\
Ca $\mathrm{a}_{\text {width }}$ & $3.5 \pm 0.5$ & $2.9 \pm 0.2$ & 0.078 \\
FTIRI parameters & & & \\
Pyr/deH-DHLNL ratio & $3.3 \pm 0.4$ & $1.9 \pm 0.2^{*}$ & 0.016 \\
Mineral maturity & $1.10 \pm 0.1$ & $1.11 \pm 0.1$ & 0.901 \\
Carbonate substitution & $0.006 \pm 0.001$ & $0.006 \pm 0.000$ & 0.934 \\
\hline$*$ p $<0.05$ vs WT animals. & & &
\end{tabular}

for leptin involvement in the observed skeletal phenotype. Furthermore, given the wide tissue-expression of the GIPR, an indirect effect via other tissues cannot be excluded.

As regard with the incretin effects of GIP, although, we did not perform oral glucose tolerance test to assess insulin response in this condition, studies performed on the same GIPR KO model that we used revealed that these animals are hypoinsulinemic in response to oral glucose challenge with a $40 \%$ reduction in plasma insulin level [17]. Insulin-deficient mice present a growth retardation that occurred predominantly in the fetal life with a decrease in bone formation [40]. Mice lacking the insulin receptor in osteoblasts have reduced bone acquisition due to decreased bone formation and deficient numbers of osteoblasts [41]. As such it is intriguing why animals with a lower insulin response do not present a similar bone phenotype. One reason might reside in the serum level or tissue-sensitivity for GLP-1. Indeed, Pamir and coworkers demonstrated in the other model of GIPR KO mice that although these animals presented with a mild impairment in glucose tolerance, the sensitivity of the pancreatic islet for GLP-1 was augmented in deficient animals as compared with WT controls [42]. In our study we did not investigate the tissue sensitivity for GLP-1, but in regard with the anabolic effect of the GLP-1 pathway in bone [43], we cannot rule out the involvement of this molecule in the observed bone phenotype.

The quality of the bone matrix was reduced in mice lacking the GIPR receptor. Thus, the intrinsic properties of the bone matrix (hardness, elasticity modulus, dissipated energy) were all reduced in deficient animals. One could wonder why the choice of nanoindentation has been preferred to more classical biomechanical tests. Three-point bending is almost exclusively performed at the midshaft femur or

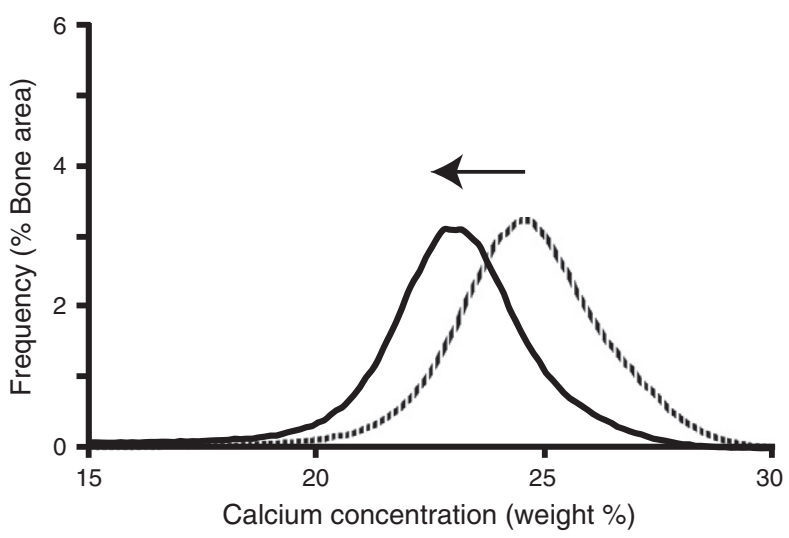

Fig. 7. Bone mineral density distribution in male wild-type (WT) and GIPR knockout (GIPR KO) animals at 16 weeks of age. Plain curve (GIPR KO) is shifted to the left as compared to dotted curve (WT). $\mathrm{N}=11-12$ in each group. tibia in mice. This location barely contains trabecular bone and as such three-point bending evaluate the biomechanical response of cortical bone not trabecular bone. Three-point bending is also highly influenced by the bone piece geometry (cortical thickness, cortical porosity, etc....) and the biomechanical parameters obtained with this methodology are a mix of geometry, microarchitecture and material intrinsic quality. Vertebral axial compression could have been an alternative to assess trabecular bone strength, but it is extremely challenging to dissect in mice only the vertebral bodies to assess the response of trabecular bone. Here again, compression tests are dependent of trabecular microarchitecture and material intrinsic quality. As the aim of the study was to investigate also material intrinsic quality, we preferred to use nanoindentation. Nanoindentation is a relatively new methodology that allows investigation of biomechanical parameters at a micro/nanoscopic level. As such, nanoindentation data are not impacted by the confounding factors such as geometry or microarchitecture and represent the intrinsic mechanical response of the bone matrix. In our study, the bone matrix appeared to be significantly hypomineralized as evidenced from BMDD parameters and a decrease in collagen cross-links was also observed, supporting the idea that in GIPR-deficient animals, bone matrix is less mature. Despite an apparent increase in trabecular bone volume, bone quality was definitely reduced in these animals and the strength of trabecular bone might be affected although it was not investigated in the present study.

In summary, deficiency in GIPR signaling in male mice led to a higher trabecular bone volume associated with an increase in trabecular number and a decrease in osteoclast numbers. These modifications of the bone microarchitecture were associated with alterations of the adipokine network. However, despite an apparent increase in bone volume, quality of the bone matrix was reduced posing the problem of bone strength. Further studies are required to understand the overall mode of action of GIP on bone and to elucidate whether targeting the GIP/GIPR pathway might represent a valuable alternative in bone therapeutics.

Supplementary data to this article can be found online at http://dx. doi.org/10.1016/j.bone.2012.11.039.

\section{Acknowledgments}

The authors are grateful to N. Gaborit and G. Brossard for their help with microCT. This work was supported by grants from Contrat Région Pays de la Loire: Bioregos2 program and the University of Ulster Proof of Principle Funding Programme.

\section{References}

[1] Elnenaei MO, Musto R, Alaghband-Zadeh J, Moniz C, Le Roux CW. Postprandial bone turnover is independent of calories above $250 \mathrm{kcal}$. Ann Clin Biochem 2010;47:318-20.

[2] Henriksen DB, Alexandersen P, Bjarnason NH, Vilsboll T, Hartmann B, Henriksen EE, et al. Role of gastrointestinal hormones in postprandial reduction of bone resorption. J Bone Miner Res 2003;18:2180-9.

[3] Andersen DK, Elahi D, Brown JC, Tobin JD, Andres R. Oral glucose augmentation of insulin secretion. Interactions of gastric inhibitory polypeptide with ambient glucose and insulin levels. J Clin Invest 1978;62:152-61.

[4] Schirra J, Katschinski M, Weidmann C, Schafer T, Wank U, Arnold R, et al. Gastric emptying and release of incretin hormones after glucose ingestion in humans. J Clin Invest 1996;97:92-103.

[5] Varner AA, Isenberg JI, Elashoff JD, Lamers CB, Maxwell V, Shulkes AA. Effect of intravenous lipid on gastric acid secretion stimulated by intravenous amino acids. Gastroenterology 1980;79:873-6.

[6] Baggio LL, Drucker DJ. Biology of incretins: GLP-1 and GIP. Gastroenterology 2007; 132:2131-57.

[7] Irwin N, Flatt PR. Therapeutic potential for GIP receptor agonists and antagonists. Best Pract Res Clin Endocrinol Metab 2009;23:499-512.

[8] Bollag RJ, Zhong Q, Phillips P, Min L, Zhong L, Cameron R, et al. Osteoblast-derived cells express functional glucose-dependent insulinotropic peptide receptors. Endocrinology 2000;141:1228-35

[9] Pacheco-Pantoja EL, Ranganath LR, Gallagher JA, Wilson PJ, Fraser WD. Receptors and effects of gut hormones in three osteoblastic cell lines. BMC Physiol 2011;11: 12. 
[10] Bollag RJ, Zhong Q, Ding KH, Phillips P, Zhong L, Qin F, et al. Glucose-dependent insulinotropic peptide is an integrative hormone with osteotropic effects. Mol Cell Endocrinol 2001;177:35-41.

[11] Zhong Q, Ding KH, Mulloy AL, Bollag RJ, Isales CM. Glucose-dependent insulinotropic peptide stimulates proliferation and TGF-beta release from MG-63 cells. Peptides 2003;24:611-6.

[12] Zhong Q Itokawa T, Sridhar S, Ding KH, Xie D, Kang B, et al. Effects of glucose-dependent insulinotropic peptide on osteoclast function. Am J Physiol Endocrinol Metab 2007;292:E543-8.

[13] Tsukiyama K, Yamada Y, Yamada C, Harada N, Kawasaki Y, Ogura M, et al. Gastric inhibitory polypeptide as an endogenous factor promoting new bone formation after food ingestion. Mol Endocrinol 2006;20:1644-51.

[14] Xie D, Cheng H, Hamrick M, Zhong Q, Ding KH, Correa D, et al. Glucose-dependent insulinotropic polypeptide receptor knockout mice have altered bone turnover. Bone 2005;37:759-69.

[15] Xie D, Zhong Q Ding KH, Cheng H, Williams S, Correa D, et al. Glucose-dependent insulinotropic peptide-overexpressing transgenic mice have increased bone mass. Bone 2007;40:1352-60.

[16] Chappard D, Basle MF, Legrand E, Audran M. New laboratory tools in the assessment of bone quality. Osteoporos Int 2011;22:2225-40.

[17] Preitner F, Ibberson M, Franklin I, Binnert C, Pende M, Gjinovci A, et al. Gluco-incretins control insulin secretion at multiple levels as revealed in mice lacking GLP-1 and GIP receptors. J Clin Invest 2004;113:635-45.

[18] Blouin S, Basle MF, Chappard D. Interactions between microenvironment and cancer cells in two animal models of bone metastasis. Br J Cancer 2008;98:809-15.

[19] Flatt PR, Bailey CJ. Abnormal plasma glucose and insulin responses in heterozygous lean (ob/+) mice. Diabetologia 1981;20:573-7.

[20] Bouxsein ML, Boyd SK, Christiansen BA, Guldberg RE, Jepsen KJ, Muller R. Guidelines for assessment of bone microstructure in rodents using micro-computed tomography. J Bone Miner Res 2010;25:1468-86.

[21] Chappard D, Alexandre C, Riffat G. Histochemical identification of osteoclasts. Review of current methods and reappraisal of a simple procedure for routine diagnosis on undecalcified human iliac bone biopsies. Basic Appl Histochem 1983;27:75-85.

[22] Parfitt AM, Drezner MK, Glorieux FH, Kanis JA, Malluche H, Meunier PJ, et al. Bone histomorphometry: standardization of nomenclature, symbols, and units. Report of the ASBMR Histomorphometry Nomenclature Committee. J Bone Miner Res 1987;2:595-610.

[23] Mieczkowska A, Basle MF, Chappard D, Mabilleau G. Thiazolidinediones induce osteocyte apoptosis by a $\mathrm{G}$ protein-coupled receptor 40-dependent mechanism. J Biol Chem 2012;287:23517-26.

[24] Mabilleau G, Chappard D, Sabokbar A. Role of the A20-TRAF6 axis in lipopolysaccharide-mediated osteoclastogenesis. J Biol Chem 2011;286:3242-9.

[25] Roschger P, Fratzl P, Eschberger J, Klaushofer K. Validation of quantitative backscattered electron imaging for the measurement of mineral density distribution in human bone biopsies. Bone 1998;23:319-26.

[26] Oliver WC, Pharr GM. An improved technique for determining hardness and elastic modulus using load and displacement sensing indentation experiments. J Mater Res 1992;7:1564-83.
[27] Paschalis EP, DiCarlo E, Betts F, Sherman P, Mendelsohn R, Boskey AL. FTIR microspectroscopic analysis of human osteonal bone. Calcif Tissue Int 1996;59: 480-7.

[28] Paschalis EP, Verdelis K, Doty SB, Boskey AL, Mendelsohn R, Yamauchi M. Spectroscopic characterization of collagen cross-links in bone. J Bone Miner Res 2001;16:1821-8.

[29] Boskey AL, DiCarlo E, Paschalis E, West P, Mendelsohn R. Comparison of mineral quality and quantity in iliac crest biopsies from high- and low-turnover osteoporosis: an FT-IR microspectroscopic investigation. Osteoporos Int 2005;16:2031-8.

[30] Karsenty G, Gershon MD. The importance of the gastrointestinal tract in the control of bone mass accrual. Gastroenterology 2011;141:439-42.

[31] Yadav VK, Oury F, Suda N, Liu ZW, Gao XB, Confavreux C, et al. A serotonindependent mechanism explains the leptin regulation of bone mass, appetite, and energy expenditure. Cell 2009;138:976-89.

[32] Harada N, Yamada Y, Tsukiyama K, Yamada C, Nakamura Y, Mukai E, et al. A novel GIP receptor splice variant influences GIP sensitivity of pancreatic beta-cells in obese mice. Am J Physiol Endocrinol Metab 2008;294:E61-8.

[33] Gremlich S, Porret A, Hani EH, Cherif D, Vionnet N, Froguel P, et al. Cloning, functional expression, and chromosomal localization of the human pancreatic islet glucosedependent insulinotropic polypeptide receptor. Diabetes 1995;44:1202-8.

[34] Yaqub T, Tikhonova IG, Lattig J, Magnan R, Laval M, Escrieut C, et al. Identification of determinants of glucose-dependent insulinotropic polypeptide receptor that interact with $\mathrm{N}$-terminal biologically active region of the natural ligand. $\mathrm{Mol}$ Pharmacol 2010;77:547-58.

[35] Boylan MO, Jepeal LI, Wolfe MM. Structure of the rat glucose-dependent insulinotropic polypeptide receptor gene. Peptides 1999;20:219-28.

[36] Yamada Y, Hayami T, Nakamura K, Kaisaki PJ, Someya Y, Wang CZ, et al. Human gastric inhibitory polypeptide receptor: cloning of the gene (GIPR) and cDNA. Genomics 1995;29:773-6.

[37] Shinoda Y, Yamaguchi M, Ogata N, Akune T, Kubota N, Yamauchi T, et al. Regulation of bone formation by adiponectin through autocrine/paracrine and endocrine pathways. J Cell Biochem 2006;99:196-208.

[38] Elefteriou F, Ahn JD, Takeda S, Starbuck M, Yang X, Liu X, et al. Leptin regulation of bone resorption by the sympathetic nervous system and CART. Nature 2005;434:514-20.

[39] Kajimura D, Hinoi E, Ferron M, Kode A, Riley KJ, Zhou B, et al. Genetic determination of the cellular basis of the sympathetic regulation of bone mass accrual. J Exp Med 2011;208:841-51.

[40] Duvillie B, Cordonnier N, Deltour L, Dandoy-Dron F, Itier JM, Monthioux E, et al Phenotypic alterations in insulin-deficient mutant mice. Proc Natl Acad Sci U S A 1997;94:5137-40.

[41] Fulzele K, Riddle RC, DiGirolamo DJ, Cao X, Wan C, Chen D, et al. Insulin receptor signaling in osteoblasts regulates postnatal bone acquisition and body composition. Cell 2010;142:309-19.

[42] Pamir N, Lynn FC, Buchan AM, Ehses J, Hinke SA, Pospisilik JA, et al. Glucosedependent insulinotropic polypeptide receptor null mice exhibit compensatory changes in the enteroinsular axis. Am J Physiol Endocrinol Metab 2003;284:E931-9.

[43] Nuche-Berenguer B, Moreno P, Esbrit P, Dapia S, Caeiro JR, Cancelas J, et al. Effect of GLP-1 treatment on bone turnover in normal, type 2 diabetic, and insulin-resistant states. Calcif Tissue Int 2009;84:453-61. 